\title{
WORLD JOURNAL OF
SURGICAL ONCOLOGY
}

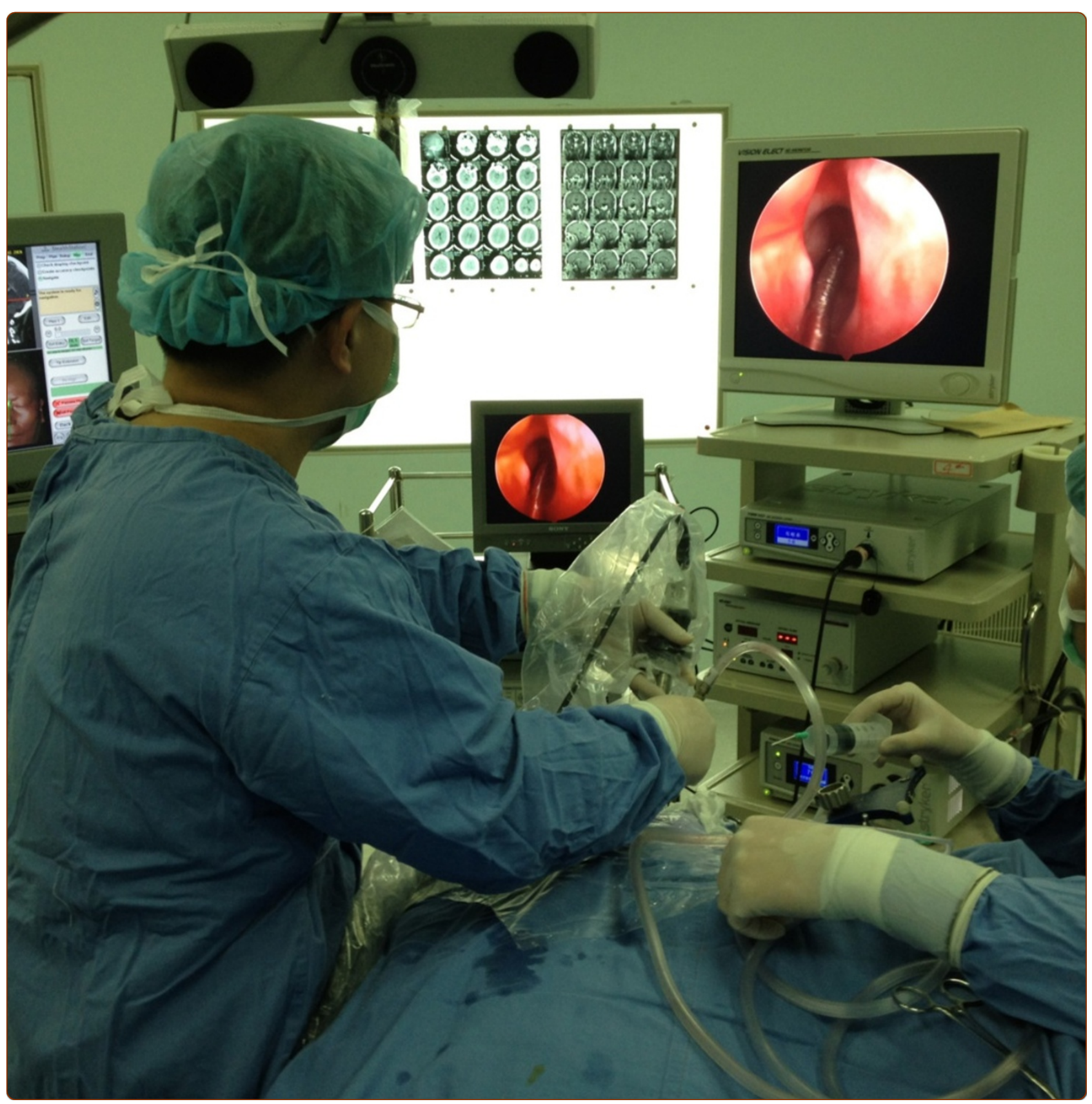

\section{Endoscopic versus microscopic transsphenoidal pituitary adenoma surgery: a meta-analysis}

Gao et al. 


\title{
Endoscopic versus microscopic transsphenoidal pituitary adenoma surgery: a meta-analysis
}

\author{
Yang Gao ${ }^{1}$, Chunlong Zhong ${ }^{1 *}$, Yu Wang ${ }^{2 *}$, Siyi Xu' ${ }^{1}$ Yang Guo ${ }^{1}$, Chenyang Dai ${ }^{1}$, Yan Zheng ${ }^{1}$, Yong Wang ${ }^{1}$,
}

Qizhong Luo ${ }^{1}$ and Jiyao Jiang ${ }^{1}$

\begin{abstract}
Background: Endoscopic transsphenoidal surgery has gradually come to be regarded as a preferred option in the treatment of pituitary adenomas because of its advantages of improved visualization and its minimal invasiveness.

The aim of this study was to compare and evaluate the outcomes and complications of endoscopic and microscopic transsphenoidal surgery in the treatment of pituitary adenomas.
\end{abstract}

Methods: We performed a systematic literature search of MEDLINE, EMBASE, the Cochrane Library and the Web of Science between January 1992 and May 2013. Studies with consecutive patients that explicitly and fully compared endoscopic and microscopic approaches in the treatment of pituitary adenomas were included.

Results: A total of 15 studies ( $n=1,014$ patients) met the inclusion criteria among 487 studies that involved endoscopic surgery and 527 studies that dealt with microscopic surgery. The rate of gross tumor removal was higher in the endoscopic group than in the microscopic group. The post-operative rates of septal perforation were less frequent in patients who underwent endoscopic surgery. There was no significant difference between the two techniques in the incidence rates of meningitis, diabetes insipidus, cerebrospinal fluid leak, epistaxis or hypopituitarism. The post-operative hospital stay was significantly shorter for the endoscopic surgery group compared with the microscopic surgery group $(P<0.05)$. There was no significant difference in the length of the operation $(P>0.05)$.

Conclusions: The present study indicates that the endoscopic transsphenoidal approach is safer and more effective than microscopic surgery in the treatment of pituitary adenomas.

Keywords: Meta-analysis, Pituitary adenoma, Endoscopic, Transsphenoidal, Microscopic

\section{Background}

In the late nineteenth century, the resection of a pituitary tumor via an open craniotomy was first described by Horsley [1]. Since then, the field of pituitary surgery has undergone constant evolution. Schloffer et al. [2] were the first to report the transsphenoidal approach in a sella tumor in 1907. It was Cushing et al. [3] who abandoned external incisions and popularized the sublabial transseptal transsphenoidal technique. In the 1960s, Hardy [4] perfected Cushing's approach with the introduction of the operative microscope. The traditional transseptal/

\footnotetext{
* Correspondence: drchunlongzhong@126.com; renjiwangyu@gmail.com 'Department of Neurosurgery, Renji Hospital, School of Medicine, Shanghai Jiao Tong University, Shanghai 200127, China

${ }^{2}$ Department of Obstetrics \& Gynecology, Renji Hospital, School of Medicine, Shanghai Jiao Tong University, Shanghai 200127, China
}

translabial approach has long been considered as the standard approach because it is associated with minimal morbidity and mortality. In recent years, with the development of endoscopic instruments and techniques, Jankowski [5] proposed a fully endoscopic approach to pituitary surgery in 1992. Currently, endoscopic transsphenoidal pituitary surgery has become a preferred alternative option because of its advantages of improved visualization and minimal invasiveness, which allows surgeons to gain access to central skull base lesions. However, the endoscope has the disadvantage of lacking the stereoscopic view obtainable with a microscope, which makes the benefits of the two techniques equivocal when comparing them in the treatment of pituitary adenomas.




The purpose of our study was to evaluate the outcomes and the complications associated with these two techniques by comparing endoscopic with microscopic surgery in the treatment of pituitary adenomas through a meta-analysis of the current relevant literature.

\section{Methods}

\section{Search strategy}

We performed a systematic search of MEDLINE, EMBASE, the Cochrane Library and the Web of Science for relevant literature between January 1992 and May 2013. We identified all relevant published and unpublished primary studies via an exhaustive search strategy. The following search terms were used: 'pituitary', 'pituitary and surgery', 'endoscopic and pituitary, 'endoscopic/endoscopy', 'microscopic/ microsurgery', 'transsphenoidal and surgery'. We browsed the abstracts and titles of primary collections and extracted all observational studies. Potentially relevant articles were considered by double evaluation. Additionally, the references of all obtained studies were reviewed for possible inclusion. The results were searched for humans and the English language.

\section{Inclusion/exclusion criteria}

Studies were deemed appropriate for inclusion if they met the following criteria: 1) a direct comparison between fully endoscopic and microscopic (sublabial, transeptal) approaches for pituitary adenoma; 2 ) retrospective studies that included consecutive patients; and 3) each compared group included 10 or more patients who had undergone surgery in the same center. The exclusion criteria were as follows: 1) endoscopic-assisted comparison studies, single-armed studies or non-human studies; and 2) non-investigative studies (technical reports, case series, letters, and comments).

The search results were assessed independently by two authors (Siyi $\mathrm{Xu}$ and Yang Guo). Any disagreement was resolved unanimously by discussion.

\section{Methodological quality}

The quality assessment of the retrospective comparative study was performed based on the Newcastle-Ottawa Scale [6], a scale that is also recommended by the Cochrane Non-Randomized Studies Methods Working Group. Each study was graded as 'I' if the score was $>6$ or as 'II' if the score was $\leqq 5$.

\section{Statistical analysis}

Review Manager, version 4.2 (Revman, The Cochrane Collaboration; Oxford, UK) was used for the metaanalysis. All outcomes considered in this study were dichotomous and, therefore, proportions with their corresponding 95\% confidence interval (CI) are reported. We chose to use the odds ratio (OR) as the summary statistic (an OR $>1$ favors the endoscopic group for gross tumor removal (GTR), whereas an OR $<1$ favors the endoscopic group for observed complications). Tests for heterogeneity were performed with the Chi-square and $\mathrm{I}^{2}$ for each meta-analysis. A fixed effects model was used when no heterogeneity $\left(P>0.05, \mathrm{I}^{2}=0 \%\right)$ or minimal heterogeneity $\left(P>0.05, \mathrm{I}^{2}<25 \%\right)$ was present, while a random effects model was applied in the presence of high heterogeneity $\left(P<0.05, \mathrm{I}^{2}>50 \%\right)$. The length of the operation and of the hospital stay were analyzed by using the equal-variance $t$-test (SPASS 19.0) and were considered significant if the $P$ value was $<0.05$. In

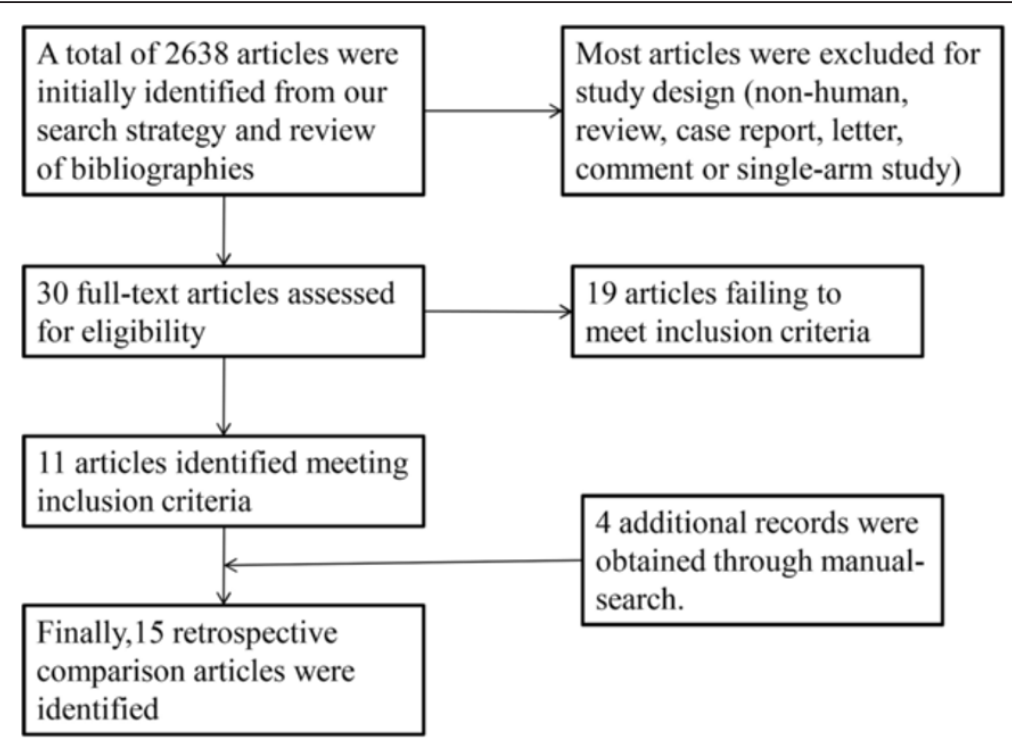

Figure 1 Flowchart diagram of the study selection process. 
Table 1 Characteristics of publication year, study type, cases in each group and GTR, length of operation and hospital stay for included studies

\begin{tabular}{|c|c|c|c|c|c|c|c|c|c|c|}
\hline \multirow[t]{2}{*}{ Study } & \multirow[t]{2}{*}{$\begin{array}{l}\text { Publication } \\
\text { year }\end{array}$} & \multirow[t]{2}{*}{$\begin{array}{l}\text { Study } \\
\text { type }\end{array}$} & \multicolumn{2}{|c|}{$\begin{array}{l}\text { Cases in each } \\
\text { group }\end{array}$} & \multicolumn{2}{|c|}{ Cases of GTR } & \multicolumn{2}{|c|}{$\begin{array}{l}\text { Length of operation } \\
\text { (mean, min) }\end{array}$} & \multicolumn{2}{|c|}{$\begin{array}{l}\text { Length of hospital stay } \\
\text { (day) }\end{array}$} \\
\hline & & & $\mathrm{E}$ & $M$ & $\mathrm{E}$ & $M$ & $\mathrm{E}$ & $M$ & $\mathrm{E}$ & $M$ \\
\hline Chen et al. [7] & 2011 & $\mathrm{RC}$ & 68 & 59 & 48 & 29 & 128 & 170 & $4.3(3$ to 12$)$ & $7.3(5$ to 22$)$ \\
\hline D'Haens et al. [8] & 2009 & $\mathrm{RC}$ & 60 & 60 & 38 & 30 & NA & NA & NA & NA \\
\hline Higgins et al. [9] & 2008 & $\mathrm{RC}$ & 16 & 25 & 14 & 20 & 117 & 152 & 3 & 5.3 \\
\hline O'Maley et al. [10] & 2008 & $\mathrm{RC}$ & 25 & 25 & $14(21)^{\mathrm{a}}$ & $17(22)^{a}$ & 176.4 & 264.6 & 3.92 (3 to 9) & 4.84 (3 to 9 ) \\
\hline Choe et al. [11] & 2008 & $\mathrm{RC}$ & 12 & 11 & 10 & 8 & NA & NA & NA & NA \\
\hline Casler et al. [12] & 2005 & $\mathrm{RC}$ & 15 & 15 & 10 & 12 & 255.33 & 245.73 & $4.4(2$ to 7$)$ & $5.73(3$ to 8$)$ \\
\hline Atkinson et al. [13] & 2008 & $\mathrm{RC}$ & 21 & 21 & 21 & 21 & NA & NA & $3.0(1$ to 10$)$ & $4.5(2$ to 9$)$ \\
\hline Sheehan et al. [14] & 1999 & $\mathrm{RC}$ & 26 & 44 & $7(16)^{a}$ & $15(36)^{a}$ & 162 & 204 & NA & NA \\
\hline White et al. [15] & 2004 & $\mathrm{RC}$ & 50 & 50 & NA & NA & NA & NA & 3.7 & 5.4 \\
\hline Razak et al. [16] & 2013 & $\mathrm{RC}$ & 40 & 40 & $15(16)^{\mathrm{a}}$ & $8(14)^{a}$ & 202 & 169 & $6 \pm 7.5$ & $8 \pm 6.7$ \\
\hline Messerer et al. [17] & 2011 & $\mathrm{RC}$ & 82 & 82 & 61 & 41 & NA & NA & NA & NA \\
\hline Cappabianca et al. [18] & 1999 & $\mathrm{RC}$ & 10 & 20 & 9 & 14 & NA & NA & $3.1 \pm 0.4$ & $6.2 \pm 0.3$ \\
\hline Koren et al. [19] & 1999 & $\mathrm{RC}$ & 20 & 20 & NA & NA & NA & NA & $3.7(3$ to 4$)$ & $7(6$ to 10$)$ \\
\hline Duz et al. [20] & 2008 & $\mathrm{RC}$ & 28 & 40 & 15 & 20 & NA & NA & NA & NA \\
\hline Neal et al. [21] & 2007 & $\mathrm{RC}$ & 14 & 15 & NA & NA & NA & NA & 3.4 & 8.3 \\
\hline
\end{tabular}

${ }^{a}$ Only the cases in brackets were followed to evaluate resection rate. $E$, endoscopic group; GTR, gross tumor removal; $M$, microscopic group; $N A$, not available; $R C$, retrospective cohort study.

addition, the effect of publication and selection bias on the summary estimates was tested by both the HarbordEgger bias indicator and Begg-Mazumdar bias indicator. A two-tailed $P$-value $<0.05$ was considered statistically significant.

\section{Analyzed items}

The primary data items for this meta-analysis were: 1) the GTR, based on either post-operative imaging and/or normalization of hormonal hypersecretion that confirmed the absence of any tumor; 2) the length of the hospital stay

Table 2 Characteristics of quality grade and cases of complications for included studies

\begin{tabular}{|c|c|c|c|c|c|c|c|c|c|c|c|c|c|}
\hline \multirow[t]{2}{*}{ Study } & \multirow[t]{2}{*}{$\begin{array}{l}\text { Quality } \\
\text { grade }\end{array}$} & \multicolumn{2}{|c|}{$\begin{array}{l}\text { Cases of } \\
\text { epistaxis }\end{array}$} & \multicolumn{2}{|c|}{$\begin{array}{l}\text { Cases of CSF } \\
\text { leak }\end{array}$} & \multicolumn{2}{|c|}{ Cases of $\mathrm{DI}$} & \multicolumn{2}{|c|}{$\begin{array}{l}\text { Cases of } \\
\text { meningitis }\end{array}$} & \multicolumn{2}{|c|}{$\begin{array}{l}\text { Cases of septal } \\
\text { perforation }\end{array}$} & \multicolumn{2}{|c|}{$\begin{array}{l}\text { Cases of } \\
\text { hypopituitarism }\end{array}$} \\
\hline & & $\bar{E}$ & $M$ & $\bar{E}$ & $M$ & $\bar{E}$ & $M$ & $\bar{E}$ & $M$ & $\bar{E}$ & $M$ & $\bar{E}$ & $M$ \\
\hline Chen et al. [7] & 1 & 1 & 1 & 3 & 2 & 2 & 3 & 0 & 1 & 1 & 2 & 0 & 1 \\
\hline D'Haens et al. [8] & 1 & 1 & 1 & 6 & 1 & NA & NA & 1 & 0 & NA & NA & 1 & 0 \\
\hline Higgins et al. [9] & 1 & 0 & 0 & 1 & 1 & 5 & 7 & NA & NA & 1 & 4 & 1 & 2 \\
\hline O'Maley et al. [10] & 1 & 0 & 0 & 3 & 1 & 1 & 4 & 0 & 1 & NA & NA & 0 & 1 \\
\hline Choe et al. [11] & 1 & 0 & 0 & 2 & 2 & 1 & 1 & 0 & 1 & NA & NA & 1 & 3 \\
\hline Casler et al. [12] & 1 & 0 & 1 & 4 & 3 & 3 & 2 & NA & NA & 0 & 3 & NA & NA \\
\hline Atkinson et al. [13] & 1 & 0 & 0 & 3 & 2 & 3 & 3 & NA & NA & NA & NA & NA & NA \\
\hline Sheehan et al. [14] & 1 & 0 & 0 & 3 & 7 & 1 & 0 & NA & NA & 0 & 2 & NA & NA \\
\hline White et al. [15] & 1 & 1 & 8 & 6 & 7 & 11 & 11 & 1 & 0 & 0 & 1 & NA & NA \\
\hline Razak et al. [16] & 1 & NA & NA & 4 & 6 & 4 & 11 & 1 & 0 & NA & NA & NA & NA \\
\hline Messerer et al. [17] & 1 & 4 & 1 & 10 & 7 & 7 & 8 & 3 & 4 & NA & NA & 5 & 9 \\
\hline Cappabianca et al. [18] & $\|$ & 0 & 0 & 0 & 0 & 4 & 2 & NA & NA & NA & NA & NA & NA \\
\hline Koren et al. [19] & $\|$ & 0 & 2 & 4 & 5 & NA & NA & NA & NA & 2 & 6 & NA & NA \\
\hline Duz et al. [20] & $\|$ & 0 & 0 & 8 & 10 & NA & NA & NA & NA & NA & NA & NA & NA \\
\hline Neal et al. [21] & $\|$ & 0 & 0 & 4 & 8 & 1 & 5 & NA & NA & NA & NA & NA & NA \\
\hline
\end{tabular}


and operative time of each operation; and 3) complications (post-operative cerebrospinal fluid (CSF) leak, diabetes insipidus (DI), hypopituitarism, meningitis, epistaxis, septal perforation).

\section{Results}

A total of 2,638 articles were initially identified using our search strategy and review of bibliographies. These articles were examined to exclude irrelevant studies, resulting in 30 potentially eligible articles. Subsequently, the full texts of these studies were examined thoroughly, and 19 articles were excluded based on their failure to meet the inclusion criteria. Four additional records which meet the inclusion criteria were obtained through a manual search. Ultimately, 15 articles retrospectively comparing endoscopic versus microscopic surgery in the treatment of pituitary adenomas were identified (Figure 1). The characteristics of the included studies are summarized in Table 1 and Table 2. All of the included reports were retrospective studies published between 1992 and 2013. A total

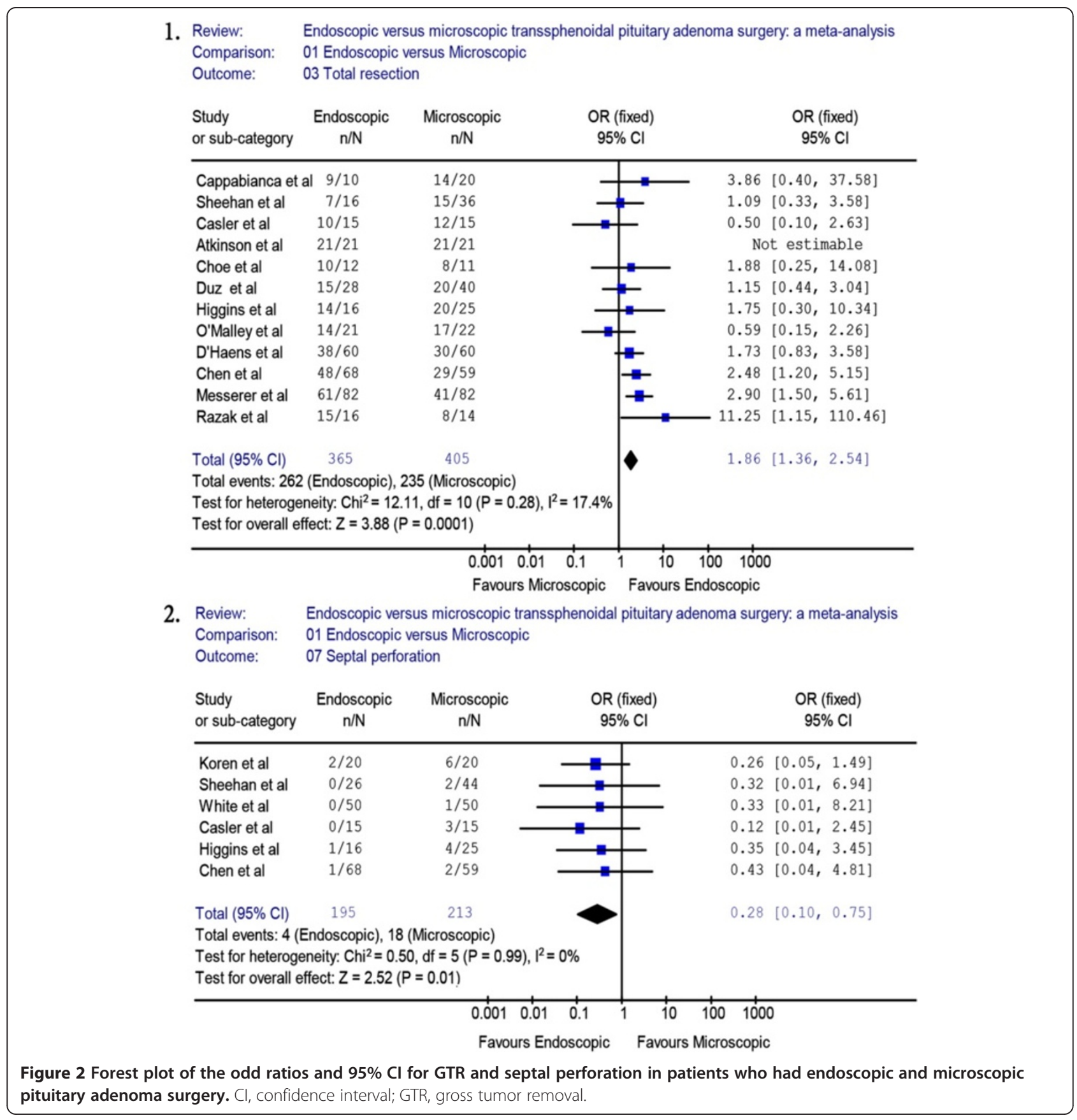


of 1,014 patients was reviewed (endoscopic group $=487$, microscopic group $=527$ ). Unfortunately, large, prospective, randomized studies comparing the two techniques were not available because of the lack of relevant reports. According to the selected criteria of methodological quality, eleven studies [7-17] were identified as grade 'I' and four studies [18-21] were identified as grade 'II'. To identify potential sources of the observed heterogeneity and to test the stability of our results, a sensitivity analysis was further performed by removing the grade 'II' studies.
Reviewing the characteristics of the surgical procedures of the included studies, O'Maley et al. [10] reported 25 cases separately in each surgery group; however, only 21 cases in the endoscopic group and 22 cases in the microscopic group were followed to evaluate the resection rate. Sixteen cases in the endoscopic group and 36 cases in the microscopic group were followed to evaluate the resection rate in Sheehan's study [14], and 16 cases in the endoscopic group and 14 cases in the microscopic group were followed to evaluate the resection

1. Review: Endoscopic versus microscopic transsphenoidal pituitary adenoma surgery. a meta-analysis

Comparison: 01 Endoscopic versus Microscopic

Outcome: $\quad 03$ Total resection

$\begin{array}{lcccc}\text { Study } & \text { Endoscopic } & \text { Microscopic } & \text { OR (fixed) } & \text { OR (fixed } \\ \text { or sub-category } & n / N & n / N & 95 \% \mathrm{Cl} & 95 \% \mathrm{Cl}\end{array}$

01 Sub-category

Sheehan et al $\quad 7 / 16 \quad 15 / 36$

Casler et al $\quad 10 / 15 \quad 12 / 15$

Atkinson et al $\quad 21 / 21 \quad 21 / 21$

$\begin{array}{llr}\text { Choe et al } & 10 / 12 & 8 / 11\end{array}$

Higgins et al $\quad 14 / 16 \quad 20 / 25$

O'Malley et al $\quad 14 / 21 \quad 17 / 22$

D'Haens et al $\quad 38 / 60 \quad 30 / 60$

Chen et al $\quad 48 / 68 \quad 29 / 59$

Messerer et al $\quad 61 / 82 \quad 41 / 82$

$\begin{array}{lcc}\text { Razak et al } & 15 / 16 & 8 / 14 \\ \text { Subtotal }(95 \% \mathrm{Cl}) & 327 & 345\end{array}$

Total events: 238 (Endoscopic), 201 (Microscopic)

Test for heterogeneity: $\mathrm{Chi}^{2}=10.75, \mathrm{df}=8(\mathrm{P}=0.22), \mathrm{I}^{2}=25.6 \%$

Test for overall effect: $Z=3.84(P=0.0001)$

\begin{tabular}{llllllll}
\hline 0.001 & 0.01 & 0.1 & 1 & 10 & 100 & 1000
\end{tabular}

Favours Microscopic Favours Endoscopic

2. Review: Endoscopic versus microscopic transsphenoidal pituitary adenoma surgery: a meta-analysis Comparison: 01 Endoscopic versus Microscopic Outcome: 01 Epistaxis

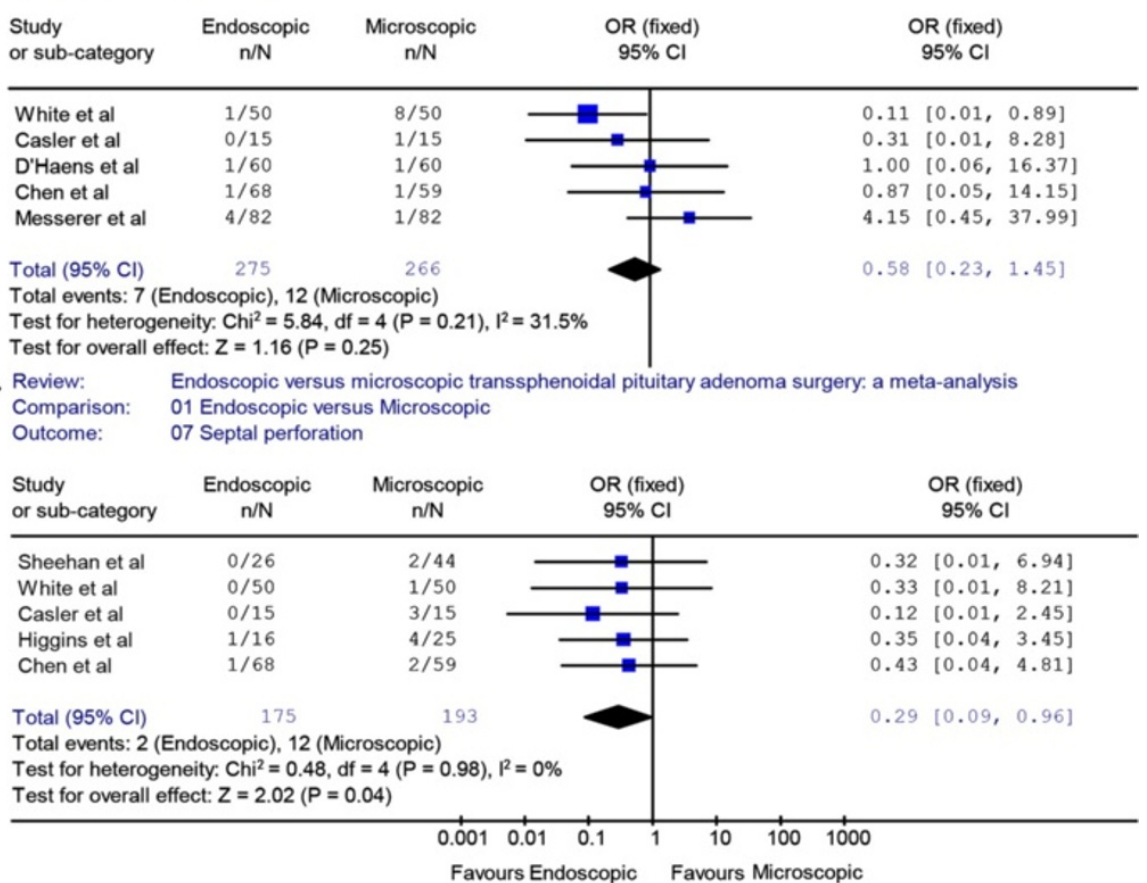

Figure 3 Sensitivity analyses of GTR, epistaxis and septal perforation. GTR, gross tumor removal. 
rate in Razak's study [16]. The hospital stay and the operative time were not available for the meta-analysis because standard deviations either were not reported by, or could not be computed for, most of the reports.

We used meta-analytical techniques to obtain pooled estimates rates of post-operative outcomes and complications. Reviewing the characteristics of the surgical procedures, twelve studies [7-14,16-18,20] (endoscopic group $=365$, microscopic group $=405$ ) reported data on GTR. A fixed effects model was used because there was no evidence of significant heterogeneity $\left(X^{2}=12.11, P=0.28\right.$, $\left.\mathrm{I}^{2}=17.4 \%\right)$. The proportion of patients with GTR was significantly different between the endoscopic group and the microscopic group ( $\mathrm{OR}=1.86,95 \% \mathrm{CI} 1.36$ to 2.54 ) (Figure 2.1). A higher rate of GTR was performed in the endoscopic group than in the microscopic group (71.8\% versus $58.0 \%)$. A sensitivity analysis was performed by removing two studies $[18,20]$, and the outcome of the analysis revealed a significant difference between the endoscopic group and the microscopic group, which was consistent with previous results $(\mathrm{OR}=1.93,95 \% \mathrm{CI} 1.38$ to 2.70) (Figure 3.1). The Begg's Test $(P=0.586)$ and Egger's Test $(P=0.590)$ showed no publication bias.

Six studies reported on post-operative septal perforation. The difference between the endoscopic and the microscopic groups was statistically significant $(\mathrm{OR}=0.28,95 \%$ 1. Review: Endoscopic versus microscopic transsphenoidal pituitary adenoma surgery. a meta-analysis
Comparison: 01 Endoscopic versus Microscopic Outcome: $\quad 02$ CSF leak

\begin{tabular}{|c|c|c|c|c|c|}
\hline $\begin{array}{l}\text { Study } \\
\text { or sub-category }\end{array}$ & $\begin{array}{l}\text { Endoscopic } \\
\mathrm{n} / \mathrm{N}\end{array}$ & $\begin{array}{c}\text { Microscopic } \\
n / N\end{array}$ & $\begin{array}{l}\text { OR (fixed) } \\
95 \% \mathrm{Cl}\end{array}$ & & $\begin{array}{l}\text { OR (fixed) } \\
95 \% \mathrm{Cl}\end{array}$ \\
\hline Koren et al & $4 / 20$ & $5 / 20$ & & 0.75 & {$[0.17,3.33]$} \\
\hline Sheehan et al & $3 / 26$ & $7 / 44$ & & 0.69 & {$[0.16,2.94]$} \\
\hline White et al & $6 / 50$ & $7 / 50$ & & 0.84 & {$[0.26,2.70]$} \\
\hline Casler et al & $4 / 15$ & $3 / 15$ & & 1.45 & {$[0.26,8.01]$} \\
\hline Atkinson et al & $3 / 21$ & $2 / 21$ & & 1.58 & {$[0.24,10.60]$} \\
\hline Neal et al & $4 / 14$ & $8 / 15$ & & 0.35 & {$[0.07,1.63]$} \\
\hline Choe et al & $2 / 12$ & $2 / 11$ & & 0.90 & {$[0.10,7.78]$} \\
\hline Duz et al & $8 / 28$ & $10 / 40$ & & 1.20 & {$[0.40,3.56]$} \\
\hline Higgins et al & $1 / 16$ & $1 / 25$ & & 1.60 & {$[0.09,27.55]$} \\
\hline O'Malley et al & $3 / 25$ & $1 / 25$ & & 3.27 & {$[0.32,33.84]$} \\
\hline D'Haens et al & $6 / 60$ & $1 / 60$ & & 6.56 & {$[0.76,56.22]$} \\
\hline Chen et al & $3 / 68$ & $2 / 59$ & & 1.32 & {$[0.21,8.15]$} \\
\hline Messerer et al & $10 / 82$ & $7 / 82$ & & 1.49 & {$[0.54,4.12]$} \\
\hline Razak et al & $4 / 40$ & $6 / 40$ & - & 0.63 & {$[0.16,2.43]$} \\
\hline Total $(95 \% \mathrm{Cl})$ & 477 & 507 & & 1.11 & {$[0.75,1.63]$} \\
\hline
\end{tabular}

Total events: 61 (Endoscopic), 62 (Microscopic)

Test for heterogeneity: $\mathrm{Chi}^{2}=7.88, \mathrm{df}=13(\mathrm{P}=0.85), \mathrm{I}^{2}=0 \%$ Test for overall effect: $Z=0.50(P=0.61)$

2. Review: Endoscopic versus microscopic transsphenoidal pituitary adenoma surgery: a meta-analysis Comparison: 01 Endoscopic versus Microscopic

Outcome: $\quad 06$ Diabetes insipidus

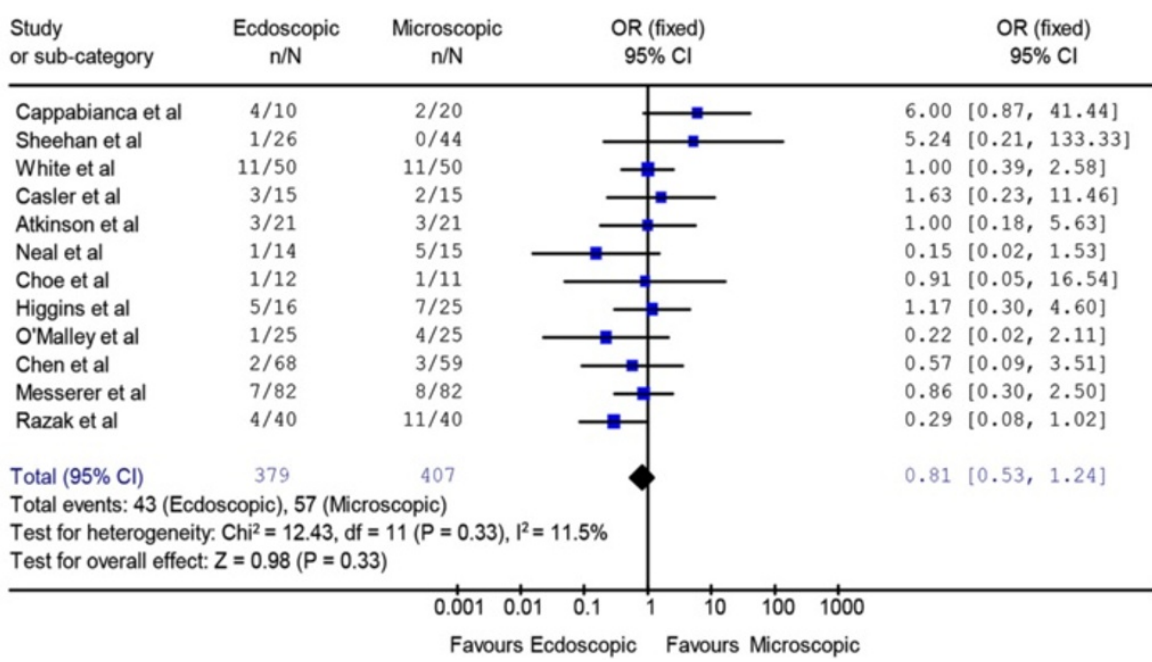

Figure 4 Forest plot of the odd ratios and $95 \% \mathrm{Cl}$ for CSF leak, DI who had endoscopic and microscopic pituitary adenoma surgery. $\mathrm{Cl}$, confidence interval; CSF, cerebrospinal fluid; DI, diabetes insipidus. 
CI 0.10 to 0.75 ) (Figure 2.2). The pooled estimate of the overall proportions for the endoscopic and microscopic groups was $2.1 \%$ versus $8.5 \%$, respectively. The proportion of septal perforation was significantly lower in those who had endoscopic surgery. A sensitivity analysis was performed by removing one study [19], and the outcome of the analysis revealed a significant difference between the endoscopic and microscopic groups, which was consistent with previous results $(\mathrm{OR}=0.29,95 \% \mathrm{CI} 0.09$ to 0.96) (Figure 3.3).

Thirteen studies (endoscopic group $=477$, microscopic group $=507$ ) reported data on CSF leak. A fixed effects model was used because there was no evidence of significant heterogeneity $\left(X^{2}=7.88, P=0.85, \mathrm{I}^{2}=0 \%\right)$. The occurrence rate of CSF leak was not significantly different between the endoscopic group and the microscopic group (OR $=1.11,95 \% \mathrm{CI} 0.75$ to 1.63 ) (Figure 4.1). The incidence rate of CSF leak in the endoscopic group was not significantly lower than in the microscopic group (12.8\% versus $12.2 \%$, respectively). A sensitivity analysis of the CSF leak was performed by removing three studies [19-21], and the outcome of the analysis did not reveal a significant difference between the endoscopic and the microscopic groups, which was consistent with previous results ( $\mathrm{OR}=1.26,95 \% \mathrm{CI} 0.8$ to 2.0$)$ (Figure 5.1). The Begg's Test $(P=0.2)$ and Egger's Test $(P=0.28)$ for CSF leak showed no publication bias.

A fixed effects model was used for DI because there was no evidence of significant heterogeneity $\left(X^{2}=12.43\right.$, $\left.P=0.33, \mathrm{I}^{2}=11.5 \%\right)$. The occurrence rate of DI was $11.3 \%$ in the endoscopic group and $14.0 \%$ in the microscopic group. The pooled estimates of the overall proportions showed no significant difference between the endoscopic and microscopic groups based on the results of 11 studies (OR $=0.81,95 \%$ CI 0.53 to 1.24$)$ (Figure 4.2). A sensitivity analysis was performed by removing two

1. Review:

Endoscopic versus microscopic transsphenoidal pituitary adenoma surgery: a meta-analysis Comparison: 01 Endoscopic versus Microscopic

Outcome: 02 CSF leak

\begin{tabular}{|c|c|c|c|c|}
\hline $\begin{array}{l}\text { Study } \\
\text { or sub-category }\end{array}$ & $\begin{array}{c}\text { Endoscopic } \\
n / N\end{array}$ & $\begin{array}{c}\text { Microscopic } \\
\mathrm{n} / \mathrm{N}\end{array}$ & $\begin{array}{l}\text { OR (fixed) } \\
95 \% \mathrm{Cl}\end{array}$ & $\begin{array}{l}\text { OR (fixed) } \\
95 \% \mathrm{Cl}\end{array}$ \\
\hline Sheehan et al & $3 / 26$ & $7 / 44$ & - & $0.69[0.16,2.94]$ \\
\hline White et al & $6 / 50$ & $7 / 50$ & & $0.84[0.26,2.70]$ \\
\hline Casler et al & $4 / 15$ & $3 / 15$ & & $1.45[0.26,8.01]$ \\
\hline Atkinson et al & $3 / 21$ & $2 / 21$ & & $1.58[0.24,10.60]$ \\
\hline Choe et al & $2 / 12$ & $2 / 11$ & & $0.90[0.10,7.78]$ \\
\hline Higgins et al & $1 / 16$ & $1 / 25$ & & $1.60[0.09,27.55]$ \\
\hline O'Malley et al & $3 / 25$ & $1 / 25$ & & $3.27[0.32,33.84]$ \\
\hline D'Haens et al & $6 / 60$ & $1 / 60$ & & $6.56[0.76,56.22]$ \\
\hline Chen et al & $3 / 68$ & $2 / 59$ & & $1.32[0.21,8.15]$ \\
\hline Messerer et al & $10 / 82$ & $7 / 82$ & & $1.49[0.54,4.12]$ \\
\hline Razak et al & $4 / 40$ & $6 / 40$ & - & $0.63[0.16,2.43]$ \\
\hline Total $(95 \% \mathrm{Cl})$ & 415 & 432 & & $1.26[0.80,2.00]$ \\
\hline \multicolumn{5}{|c|}{$\begin{array}{l}\text { Total events: } 45 \text { (Endoscopic), } 39 \text { (Microscopic) } \\
\text { Test for heterogeneity: Chi }{ }^{2}=5.36, d f=10(P=0.87), R^{2}=0 \% \\
\text { Test for overall effect: } Z=0.99(P=0.32)\end{array}$} \\
\hline
\end{tabular}

2. Review: Endoscopic versus microscopic transsphenoidal pituitary adenoma surgery: a meta-analysis Comparison: 01 Endoscopic versus Microscopic Outcome: $\quad 06$ Diabetes insipidus

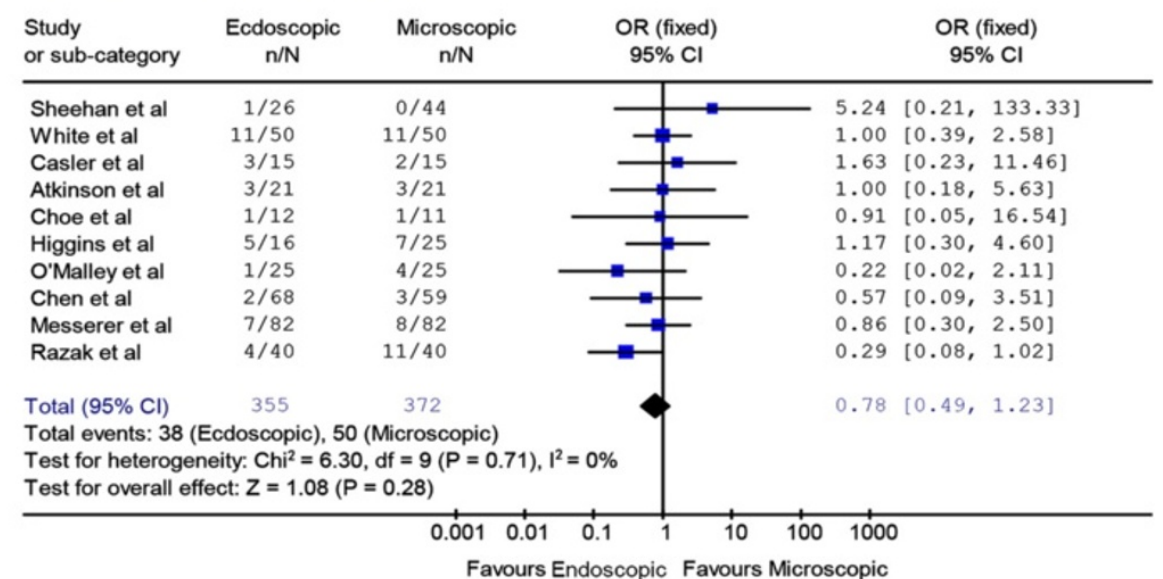

Figure 5 Sensitivity analyses of CSF leak and DI. CSF, cerebrospinal fluid; DI, diabetes insipidus. 
studies $[18,21]$, and the outcome of the analysis did not reveal a significant difference between the endoscopic and the microscopic groups, which was consistent with previous results $(\mathrm{OR}=0.78,95 \% \mathrm{CI} 0.49$ to 1.23$)$ (Figure 5.2). The Begg's Test $(P=0.89)$ and Egger's Test $(P=0.81)$ for DI indicated that there was no publication bias.

Six studies reported data on pituitary hypopituitarism. A fixed effects model was used because there was no evidence of significant heterogeneity $\left(X^{2}=1.85, P=0.87\right.$, $\left.\mathrm{I}^{2}=0 \%\right)$. In those studies, we found that the proportion of pituitary dysfunction was $3 \%$ in the endoscopic group and $6.1 \%$ in the microscopic group. The endoscopic approach appeared to reduce the occurrence rate of hypopituitarism. However, the pooled estimates of the metaanalysis showed that there was no significant difference between the two groups for the rate of complications $(\mathrm{OR}=0.53,95 \%$ CI 0.23 to 1.20$)$ (Figure 6.1$)$.

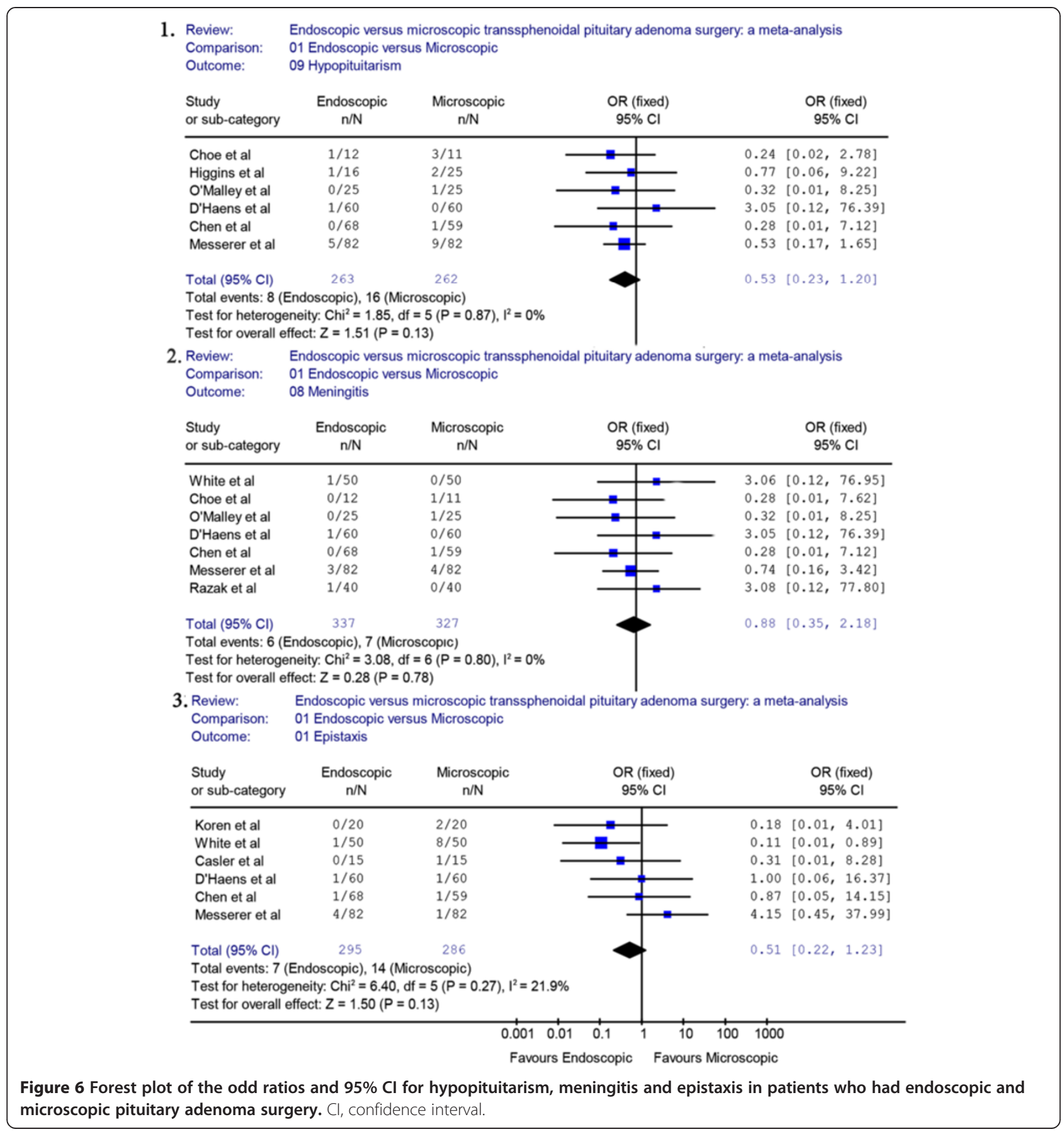


Seven studies reported data on post-operative meningitis. A fixed effects model was used because there was no evidence of significant heterogeneity $\left(X^{2}=3.08, P=0.80\right.$, $\left.\mathrm{I}^{2}=0 \%\right)$. The pooled complication OR for meningitis indicated that the occurrence rate of meningitis was not significantly different between the endoscopic and the microscopic groups $(\mathrm{OR}=0.88,95 \% \mathrm{CI} 0.35$ to 2.18 ) (Figure 6.2).

The proportion of patients with post-operative epistaxis was not significantly different between the endoscopic group and the microscopic group (OR $=0.51,95 \%$ CI 0.22 to 1.23 ) (Figure 6.3). The proportion of epistaxis was not significantly different between the endoscopic and the microscopic groups (2.4\% versus $4.9 \%)$. A sensitivity analysis was performed by removing one study [19], and the outcome of the analysis revealed no difference between the endoscopic and microscopic groups, which was consistent with previous results $(\mathrm{OR}=0.58$, 95\% CI 0.23 to 1.45 ) (Figure 3.2).

A total of six endoscopic studies reported data on the length of operation with a mean time of $173 \pm 5$ minutes versus $201 \pm 46$ minutes for the microscopic groups (Table 3 ). The difference was not statistically significant $(P=0.259)$. However, 10 endoscopic studies reported data on the hospital stay that showed a mean time of $3.8 \pm 0.9$ days in the endoscopic group while $6.3 \pm$ 1.3 days in the microscopic group, respectively. The difference between the two approaches was statistically significant $(P=0.0002)$, and the hospital stay was significantly shorter in the endoscopic group than in the microscopic group.

\section{Discussion}

Over the last century, pituitary adenoma surgery has evolved from a craniotomy approach toward less invasive approaches. In the past twenty years, there is growing evidence to support the use of endoscopic techniques as an alternative approach in the treatment of pituitary

\begin{tabular}{|c|c|c|c|}
\hline & $\begin{array}{l}\text { Endoscopic } \\
\text { group }\end{array}$ & $\begin{array}{l}\text { Microscopic } \\
\text { group }\end{array}$ & $P$ Value $^{\mathrm{a}}$ \\
\hline \multicolumn{4}{|l|}{ Length of operation } \\
\hline Mean time, min & $173 \pm 5$ minutes & $201 \pm 46$ minutes & 0.349 \\
\hline $\begin{array}{l}\text { Total number of } \\
\text { studies }\end{array}$ & $6^{b}(190)$ & $6^{\mathrm{b}}(208)$ & \\
\hline \multicolumn{4}{|l|}{ Length of hospital stay } \\
\hline Mean time, days & $3.8 \pm 0.9$ days & $6.3 \pm 1.3$ days & $P=0.00017$ \\
\hline Total numberof studies & $10^{c}(239)$ & $10^{c}(250)$ & \\
\hline
\end{tabular}

${ }^{\mathrm{a}}$ Statistical analysis performed using equal-variance $t$-test; ${ }^{\mathrm{b}}$ References $[7,9-11,14,16] ;{ }^{C}$ References $[7,9,10,12,13,15,16,18,19,21]$. adenomas [16,22-26]. Endoscopy can expand the limits of the surgeons' performance of transsphenoidal surgery, improving visualization and removing tumors that they could not access before. It is likely that its characteristic of minimal invasiveness explains the positive outcomes and lower proportion of post-operative complications of endoscopic procedures in comparison with the microscopic approach.

Several authors have discussed the potential outcomes of the endoscopic technique. DeKlotz et al. [22] used a meta-analysis to reveal the superior rate of GTR (79\% versus $65 \%, P<0.0001$ ) as well as the lower rates of CSF leak (5\% versus $7 \%, P<0.01)$, septal perforation $(0 \%$ versus $5 \%$ ) and post-operative epistaxis (1\% versus $4 \%$, $P<0.0001)$ for the endoscopic approach compared with the sublabial approach. Rotenberg et al. [23] concluded that the two approaches had similar outcomes (GTR, hormonal abnormality resolution) but that the endoscopic approach was associated with fewer complications as well as a shorter hospital stay and length of operation. Goudakos et al. [24] demonstrated that the rates of GTR/CSF leakage were similar between the two techniques. However, the study also revealed a lower incidence of post-operative DI and a shorter hospital stay in the studied endoscopic groups. Other systematic reviews also support the safety and short-term efficacy of endoscopic pituitary surgery [16,25]. Interestingly, Ammirati et al. [27] recently reported a meta-analysis concluding that endoscopic removal of pituitary adenoma, in the short term, does not seem to confer any advantages over the microscopic technique and the incidence of vascular complications was higher with endoscopic than with microscopic removal of pituitary adenomas.

How can the reported difference be explained? The primary explanation is that most of the previous reports pertain to single-armed studies in the absence of a reliable comparison. Second, the inclusion and exclusion criteria are key factors in each study, which may lead to different conclusions. In addition, the complication rate in microscope-based surgery is already low and the rates of GTR are high. Demonstrating a statistically significant difference between endoscopic and microscopic techniques will require a larger number of cases. Furthermore, a learning curve $[28,29]$ is anticipated because the endoscopic approach is a newer technique, and gradual improvement in outcomes will occur as the cumulative experience increases over time. Future studies are required to resolve the learning curve issues.

However, Doglietto et al. [30] reported that it may not be the time to conduct meta-analyses of endoscopic skull base surgery but it is certainly an appropriate time to collected data prospectively. As we know, the development of a new surgical technique often begets criticism due to the possibility of a learning curve. To date, 
no large, prospective, randomized study has been performed to compare outcomes between endoscopic and microsurgical transsphenoidal techniques. We believe that the endoscopic technique, after a first phase of un-acceptance, will prove its efficacy or superiority to 'classic' techniques and a systematic retrospective study of published results to compare microsurgical and endoscopic techniques in the treatment of pituitary adenomas may provide important significant guidance for further research.

The results of our meta-analysis clearly favor the endoscopic approach for pituitary surgery over the microscopic approach. The endoscopic approach yielded a significantly improved rate of GTR with lower rate of post-operative septal perforation and a shorter length of hospital stay. There were no significant differences between the two approaches for meningitis, epistaxis, DI, CSF leak, hypopituitarism and the overall length of operation time. It is important to recognize that the above analysis represents only the results of early outcomes and complications. There are few published long-term studies following these patients beyond the initial postoperative period.

The endoscopic technique appears to provide a higher rate of GTR compared with microscopic resection. The results from our analysis showed that the rate of GTR was significantly higher in the endoscopic group than in the microscopic group (71.8\% versus 58.0\%). Unfortunately, a subgroup analysis of the GTR based on the size of the pituitary adenoma was not feasible in our analysis because of the lack of available data. The actual size of the tumors was not recorded in most reports. When size was reported, it was infrequently correlated to actual surgical outcomes.

The primary complication for the majority of patients undergoing pituitary surgery is CSF leak. The currently accepted view is that the success of reconstructive techniques following dissection should be a major determinant of post-operative CSF leak [18]. Endoscopy appears to have a huge advantage in reconstruction because it improves visualization. However, in our study, the rate of post-operative leaks was similar (12.8\% versus $12.2 \%$ for the endoscopic and microscopic groups, respectively). The main reason for this similarity may be that the improved exposure during endoscopic surgery would encourage the surgeons to extend the limits of their operation more aggressively, which may offset the minimally invasive nature of endoscopic resections and increase the rate of postoperative CSF leak.

It is important to note that there are some potential limitations to this study. First, only English-language articles were considered, which means that some relevant studies in other languages may have been omitted from our meta-analysis; this may have introduced a language bias. In addition, all of the studies in our analysis are retrospective studies, which are associated with several methodological issues including selection bias, incomplete data, and a lack of standardization in the study intervention. Unfortunately, large randomized prospective studies comparing the two techniques are not available at present. Moreover, publications to date represent the results of short-term outcomes and complications. There are few published long-term studies that follow these patients beyond the initial post-operative period. Therefore, we expect our conclusions to be interpreted with caution.

\section{Conclusions}

In conclusion, the results of our meta-analysis support the safety and short-term effectiveness of endoscopic transsphenoidal pituitary adenoma surgery. The endoscopic approach is associated with a higher rate of GTR, decreased hospital stay and reduced observed post-operative complication (septal perforation). Future studies with a long-term follow-up are required to determine the outcomes and complications of endoscopic pituitary surgery.

\section{Abbreviations}

Cl: confidence interval; CSF: cerebrospinal fluid; DI: diabetes insipidus; GTR: gross tumor removal; NA: not available; OR: odds ratio; RC: retrospective cohort study.

\section{Competing interests}

The authors declare that they have no competing interests.

\section{Authors' contributions}

CZ and YW designed the study; YG drafted the manuscript; SX and YG searched the papers and extracted the data; $Y G$ and CD participated in the statistical analysis; YZ, YW, QL and JJ assisted in the critical appraisal of the included studies. All authors read and approved the final manuscript.

\section{Acknowledgements}

The authors are supported by the Shanghai Rising-Star Program (10QH1401700), funded by the Shanghai Science and Technology Commission, and the 'ShuGuang' project (09SG20), funded by the Shanghai Municipal Education Commission and the Shanghai Education Development Foundation, China.

Received: 1 August 2013 Accepted: 14 March 2014

Published: 11 April 2014

\section{References}

1. Horsley V: Remarks on ten consecutive cases of operations upon the brain and cranial cavity to illustrate the details and safety of the method employed. Br Med J 1887, 1:863-865.

2. Schloffer $\mathrm{H}$ : Erfolgreiche operation eines hypophysentumors auf nasalem wege. Wien Klin Wochenschr 1907, 20:621-624.

3. Cushing H: Intracranial Tumors: Notes Upon a Series of Two-Thousand Verified Cases With Surgical-Mortality Percentages Pertaining Thereto. Springfield, IL: Charles C Thomas; 1932:69-79.

4. Hardy J: Transsphenoidal removal of pituitary adenomas. Union Med Can 1962, 91:933-945.

5. Jankowski R, Auque J, Simon C, Marchal JC, Hepner H, Wayoff M: Endoscopic pituitary tumor surgery. Laryngoscope 1992, 102:198-202.

6. Wells GA, Shea B, O'Connell D, Peterson J, Welch V, Losos M, Tugwell P: The Newcastle-Ottawa Scale (NOS) for assessing the quality if nonrandomized studies in meta-analyses. 2008. Available at: http:// www.ohri.ca/programs/clinical_epidemiology/oxford.htm. 
7. Cheng RX, Tian HL, Gao WW, Li ZQ: A comparison between endoscopic transsphenoidal surgery and traditional transsphenoidal microsurgery for functioning pituitary adenomas. J Int Med Res 2011, 39:1985-1993.

8. D'Haens J, Van Rompaey K, Stadnik T, Haentjens P, Poppe K, Velkeniers B: Fully endoscopic transsphenoidal surgery for functioning pituitary adenomas: a retrospective comparison with traditional transsphenoidal microsurgery in the same institution. Surg Neurol 2009, 72:336-340.

9. Higgins TS, Courtemanche C, Karakla D, Strasnick B, Singh RV, Koen JL, Han JK: Analysis of transnasal endoscopic versus transseptal microscopic approach for excision of pituitary tumors. Am J Rhinol 2008, 22:649-652.

10. O'Malley BW Jr, Grady MS, Gabel BC, Cohen MA, Heuer GG, Pisapia J, Bohman LE, Leibowitz JM: Comparison of endoscopic and microscopic removal of pituitary adenomas: single-surgeon experience and the learning curve. Neurosurg Focus 2008, 25:E10.

11. Choe JH, Lee KS, Jeun SS, Cho JH, Hong YK: Endocrine outcome of endoscopic endonasaltranssphenoidal surgery in functioning pituitary adenomas. J Korean Neurosurg Soc 2008, 44:151-155.

12. Casler JD, Doolittle AM, Mair EA: Endoscopic surgery of the anterior skull base. Laryngoscope 2005, 115:16-24.

13. Atkinson $J L$, Young WF Jr, Meyer FB, Davis DH, Nippoldt TB, Erickson D, Vella A, Natt N, Abboud CF, Carpenter PC: Sublabialtransseptal vs transnasal combined endoscopic microsurgery in patients with Cushing disease and MRI-depicted microadenomas. Mayo Clin Proc 2008, 83:550-553.

14. Sheehan MT, Atkinson JL, Kasperbauer JL, Erickson BJ, Nippoldt TB: Preliminary comparison of the endoscopic transnasal vs the sublabialtransseptal approach for clinically nonfunctioning pituitary macroadenomas. Mayo Clin Proc 1999, 74:661-670.

15. White DR, Sonnenburg RE, Ewend MG, Senior BA: Safety of minimally invasive pituitary surgery (MIPS) compared with a traditional approach. Laryngoscope 2004, 114:1945-1948.

16. Razak AA, Horridge M, Connolly DJ, Warren DJ, Mirza S, Muraleedharan V, Sinha S: Comparison of endoscopic and microscopic transsphenoidal pituitary surgery: early results in a single centre. Br J Neurosurg 2013, 27:40-43.

17. Messerer M, De Battista JC, Raverot G, Kassis S, Dubourg J, Lapras V, Trouillas J, Perrin G, Jouanneau E: Evidence of improved surgical outcome following endoscopy for nonfunctioning pituitary adenoma removal. Neurosurg Focus 2011, 30:E11.

18. Cappabianca P, Alfieri A, Colao A, Ferone D, Lombardi G, de Divitiis E: Endoscopic endonasaltranssphenoidal approach: an additional reason in support of surgery in the management of pituitary lesions. Skull Base Surg 1999, 9:109-117.

19. Koren I, Hadar T, Rappaport ZH, Yaniv E: Endoscopic transnasaltranssphenoidal microsurgery versus the sublabial approach for the treatment of pituitary tumors: endonasal complications. Laryngoscope 1999, 109:1838-1840.

20. Duz B, Harman F, Secer HI, Bolu E, Gonul E: Transsphenoidal approaches to the pituitary: a progression in experience in a single centre. Acta Neurochir 2008, 150:1133-1138.

21. Neal JG, Patel SJ, Kulbersh JS, Osguthorpe JD, Schlosser RJ: Comparison of techniques for transsphenoidal pituitary surgery. Am J Rhinol 2007, 21:203-206

22. DeKlotz TR, Chia SH, Lu W, Makambi KH, Aulisi E, Deeb Z: Meta-analysis of endoscopic versus sublabial pituitary surgery. Laryngoscope 2012, 122:511-518.

23. Rotenberg B, Tam S, Ryu WH, Duggal N: Microscopic versus endoscopic pituitary surgery: a systematic review. Laryngoscope 2010, 120:1292-1297.

24. Goudakos JK, Markou KD, Georgalas C: Endoscopic versus microscopic transsphenoidal pituitary surgery: a systematic review and meta-analysis. Clin Otolaryngol 2011, 36:212-220.

25. Tabaee A, Anand VK, Barron Y, Hiltzik DH, Brown SM, Kacker A, Mazumdar M, Schwartz TH: Endoscopic pituitary surgery: a systematic review and meta-analysis. J Neurosurg 2009, 111:545-554.

26. Shah S, Har-El G: Diabetes insipidus after pituitary surgery:incidence after traditional versus endoscopic transsphenoidal approaches. Am J Rhinol 2001, 15:377-379.

27. Ammirati M, Wei L, Ciric I: Short-term outcome of endoscopic versus microscopic pituitary adenoma surgery: a systematic review and meta-analysis. J Neurol Neurosurg Psychiatry 2013, 84:843-849.
28. Koc K, Anik I, Ozdamar D, Cabuk B, Keskin G, Ceylan S: The learning curve in endoscopic pituitary surgery and our experience. Neurosurg Rev 2006, 29:298-305.

29. Leach P, Abou-Zeid AH, Kearney T, Davis J, Trainer PJ, Gnanalingham KK: Endoscopic transsphenoidal pituitary surgery: evidence of an operative learning curve. Neurosurgery 2010, 67:1205-1212.

30. Doglietto F, Maira G: Endoscopic skull base surgery: probably not the time for meta-analyses but certainly for prospectively collected data. World Neurosurg 2013, 80:784-786.

doi:10.1186/1477-7819-12-94

Cite this article as: Gao et al:: Endoscopic versus microscopic

transsphenoidal pituitary adenoma surgery: a meta-analysis. World Journal of Surgical Oncology 2014 12:94.

\section{Submit your next manuscript to BioMed Central and take full advantage of:}

- Convenient online submission

- Thorough peer review

- No space constraints or color figure charges

- Immediate publication on acceptance

- Inclusion in PubMed, CAS, Scopus and Google Scholar

- Research which is freely available for redistribution 